\section{JURNAL EKONOMI EFEKTIF}

ISSN : $2622-8882$, E-ISSN : 2622-9935

Jurnal Ekonomi Efektif, Vol. 1, No. 4, Juli 2019

@) Prodi Manajemen Fakultas Ekonomi Universitas

Pamulang

\title{
PENGARUH MOTIVASI TERHADAP PRODUKTIVITAS KARYAWAN PADA PT. ASURANSI BINTANG TBK DI JAKARTA
}

\author{
Makmur Solahudin \\ Depok Institute, Jawa Barat, Indonesia \\ *makmursolahudin@gmail.com
}

\begin{abstract}
ABSTRAK
Penelitian ini bertujuan untuk mengetahui pengaruh motivasi terhadap produktivitas karyawan pada PT. Asuransi Bintang Tbk di Jakarta. Metode yang digunakan adalah explanatory research dengan sampel sebanyak 87 responden. Teknik analisis menggunakan analisis statistik dengan pengujian regresi, korelasi, determinasi dan uji hipotesis. Hasil penelitian ini variabel motivasi diperoleh nilai rata-rata skor sebesar 3,385 dengan kriteria baik. Variabel produktivitas karyawan diperoleh nilai rata-rata skor sebesar 3,800 dengan kriteria baik. Motivasi berpengaruh positif dan signifikan terhadap produktivitas karyawan dengan nilai persamaan regresi $\mathrm{Y}=11,441+0,785 \mathrm{X}$, dan nilai koefisien korelasi 0,758 atau memiliki tingkat hubungan yang kuat dengan nilai determinasi 57,4\%. Uji hipotesis diperoleh signifikansi $0,000<0,05$.
\end{abstract}

Kata Kunci: Motivasi, Produktivitas Karyawan.

\section{ABSTRACT}

This study aims to determine the effect of motivation on employee productivity at PT. Asuransi Bintang Tbk in Jakarta. The method used is explanatory research with a sample of 87 respondents. The analysis technique uses statistical analysis with regression testing, correlation, determination and hypothesis testing. The results of this study the motivation variable obtained an average score of 3.385 with good criteria. Employee productivity variables obtained an average score of 3,800 with good criteria. Motivation has a positive and significant effect on employee productivity with the regression equation $Y=11.441+0.785 X$, and a correlation coefficient value of 0.758 or has a strong level of relationship with a determination value of $57.4 \%$. Hypothesis testing obtained a significance of $0.000<0.05$.

Keywords: Motivation, Employee Productivity. 


\section{PENDAHULUAN}

\section{A. Latar Belakang Masalah}

Perusahaan merupakan suatu organisasi yang mempunyai berbagai macam tujuan. Aktivitas suatu perusahaan dalam pencapaian tujuan tersebut diperlukan pengelolaan faktorfaktor produksi yang terdiri dari sumber daya alam, sumber daya manusia, modal, bahan baku, mesin, teknologi. Perusahaan harus selalu memperhatikan keterkaitan antara faktorfaktor produksi tersebut, dengan demikian perusahaan dituntut untuk dapat mengelola dengan sebaik-baiknya terutama dalam bidang sumber daya manusia sehingga mampu bekerja lebih efektif dan efisien. Suatu organisasi dapat berjalan efektif apabila fungsifungsi manajemen seperti perencanaan (planning), pengorganisasian (organizing), pengarahan (actuating) dan pengendalian (controlling) apabila semua itu berfungsi dengan baik, serta unsur-unsur penunjangnya tersedia dan memenuhi persyaratan.

Pentingnya sumber daya manusia ini perlu disadari oleh semua tingkatan manajemen di perusahaan.Sumber daya manusia merupakan suatu organisasi karena sumber daya memiliki bakat, tenaga dan kreativitas yang sangat dibutuhkan oleh perusahaan untuk mencapai tujuannya. Majunya teknologi, berkembangnya informasi, tersedianya modal dan memadai bahan, namun jika tanpa sumber daya manusia, maka akan sulit bagi organisasi untuk mencapai tujuan tersebut.

Salah satu produk jasa terkemuka dalam bidang asuransi adalah asuransi jiwa, dimana asuransi jiwa merupakan salah satu hal yang sangat penting karena sebagai salah satu instrumen yang dapat digunakan untuk meminimalisasi resiko yang mungkin terjadi dalam kehidupan.

Mekanisme perlindungan yang diberikan oleh pihak perusahaan asuransi sangat dibutuhkan, baik dalam dunia bisnis yang penuh dengan resiko dimana recara rasional para pelaku bisnis akan mempertimbangkan usaha untuk mengurangi resiko yang dihadapi. Salah satu faktor yang ikut menentukan tercapai atau tidaknya tujuan perusahaan adalah strategi perusahaan dalam memberikan harga. Harga dianggap sebagai salah satu faktor yang menentukan bagi perusahaan, namun setiap perusahaan hendaknya mempertimbangkan secara matang setiap keputusan yang diambil dan mengoptimalkan semua sumberdaya yang dimiliki.

Motivasi dapat diartikan sebagai kekuatan baik yang berasal dari dalam diri maupun dari luar diri seseorang yang mendorong berperilaku kerja sesuai dengan ketentuan, intensitas dan jangka waktu tertentu yang berhubungan dengan motivasi intrinsik dan ekstrinsik dalam melaksanakan pekerjaan. Menurut David McCleland dalam Miftah Toha (2012:235) mengemukakan "Motivasi merupakan seperangkat kekuatan baik yang berasal dari dalam diri maupun dari luar diri seseorang yang mendorong untuk memulai berperilaku kerja sesuai dengan format, arah, intensitas dan jangka waktu tertentu".

Sangat penting perusahaan memastikan karyawannya memiliki motivasi dalam bekerja. Motivasi merupakan proses yang terus menerus, keinginan yang tidak terpuaskan dan berakhir dengan kepuasan dengan perilaku pencarian diarahkan kepada tujuan sebagai dari proses. Dalam pelaksanaannya pimpinan harus memperhatikan faktor internal maupun eksternal baik itu dari mulai perekrutan, penempatan dan pelatihan sehingga dapat memotivasi karyawan dengan sebaik-baiknya sehingga karyawan dapat memberikan produktivitas kerja karyawan yang baik pada perusahaan. Individu yang memiliki motivasi tinggi dapat dilihat dari indikator seperti mengambil inisiatif dan mempunyai komitmen yang tinggi, loyal dan bekerja secara produktif, mempunyai kemauan yang keras, tanpa pengawasan, mengambil tindakan yang perlu, suka tantangan, disiplin, tanggungjawab, percaya diri serta mempunyai semangat. 
Dalam meningkatkan produktivitas kerja karyawan karyawan yaitu dalam pemberian motivasi. Motivasi penting diberikan kepada karyawan karena akan membangkitkan semangat untuk bekerja dan menghasilkan produktivitas kerja karyawan yang tinggi. Motivasi dapat diartikan sebagai kekuatan baik yang berasal dari dalam diri maupun dari luar diri seseorang yang mendorong berperilaku kerja sesuai dengan ketentuan, intensitas dan jangka waktu tertentu yang berhubungan dengan motivasi intrinsik dan ekstrinsik dalam melaksanakan pekerjaan. Pentingnya motivasi kerja bagi suatu perusahaan yakni sebagai faktor pendorong karyawan. Setiap aktifitas yang dilakukan seseorang pasti memiliki faktor yang mendorong aktifitas tersebut. Oleh karena itu faktor pendorongnya adalah kebutuhan serta keinginan karyawan tersebut. Kinerja dapat dinilai dari motivasi kerja karyawannya. Salah satu motivasi yang diberikan oleh perusahaan adalah pemberian kompensasi yang sesuai dari kinerja yang dihasilkan dalam menyelesaikan tugas karyawan tersebut.

Hakekatnya pemberian motivasi berarti telah memberikan kesempatan terhadap karyawan untuk bekerja dengan baik dan mendapatkan apa yang diharapkan, sehingga karyawan bisa dan mampu mengembangkan kemampuan. Motivasi secara sederhana dapat dirumuskan sebagai kondisi ataupun tindakan yang mendorong seseorang untuk melakukan suatu pekerjaan atau kegiatan semaksimal mungkin karyawan untuk berbuat dan berproduksi. Peranan motivasi adalah untuk mengintensifkan hasrat dan keinginan tersebut, oleh karena itu dapat disimpulkan bahwa usaha peningkatan semangat kerja seseorang akan selalu terkait dengan usaha memotivasinya sehingga untuk mengadakan motivasi yang baik perlu mengetahui kebutuhan-kebutuhan manusia.Menurut David McCleland dalam Miftah Toha (2012:235) mengemukakan "Motivasi merupakan seperangkat kekuatan baik yang berasal dari dalam diri maupun dari luar diri seseorang yang mendorong untuk memulai berperilaku kerja sesuai dengan format, arah, intensitas dan jangka waktu tertentu".

Berdasarkan latar belakang permasalahan diatas, maka penulis tertarik untuk melakukan penelitian lebih lanjut dengan judul: "Pengaruh Motivasi Terhadap Produktivitas Karyawan Pada PT. Asuransi Bintang Tbk di Jakarta"

\section{B. Rumusan Masalah}

1. Bagaimana motivasi pada PT. Asuransi Bintang Tbk di Jakarta ?.

2. Bagaimana produktivitas karyawan pada PT. Asuransi Bintang Tbk di Jakarta?.

3. Adakah pengaruh antara motivasi terhadap produktivitas karyawan pada PT. Asuransi Bintang Tbk di Jakarta?.

\section{Tujuan Penelitian}

1. Untuk mengetahui kondisi motivasi pada PT. Asuransi Bintang Tbk di Jakarta.

2. Untuk mengetahui kondisi produktivitas karyawan pada PT. Asuransi Bintang Tbk di Jakarta.

3. Untuk mengetahui pengaruh antara motivasi terhadap produktivitas karyawan pada PT. Asuransi Bintang Tbk di Jakarta.

\section{TINJAUAN PUSTAKA}

\section{Motivasi}

Yang dimaksud motivasi dalam penelitian ini pemberian daya penggerak yang menciptakan kegairahan kerja seseorang, agar mereka mau bekerja sama, bekerja efektif dan terintegrasi dengan segala upayanya untuk mencapai kepuasan dalam bekerja. Maslow dalam Sutrisno 
(2014:55). Adapun indikator yang digunakan meliputi: Kebutuhan fisiologis, kebutuhan rasa aman, kebutuhan sosial, kebutuhan penghargaan dan kebutuhan aktualisasi diri.

\section{Produktivitas Karyawan}

Produktivitas karyawan yang diartikan sebagai suatu ukuran dari pada hasil kerja atau kinerja seseorang dengan proses input sebagai masukan dan output sebagai keluarannya yang merupakan indikator dari pada kinerja karyawan dalam menentukan bagaimana usaha untuk mencapai produktivitas kerja karyawan yang tinggi dalam suatu organisasi. (Sedarmayanti, 2013:79). Adapun indikator yang digunakan meliputi: Tindakan konstruktif, Percaya pada diri sendiri, Bertanggung jawab, Mampu mengatasi masalah, Mempunyai kontribusi positif pada perusahaan.

\section{METODE PENELITIAN}

\section{Populasi}

Populasi dalam penelitian ini berjumlah 87 responden PT. Asuransi Bintang Tbk di Jakarta

2. Sampel

Teknik pengambilan sampling dalam penelitian ini adalah sampel jenuh, dimana semua anggota populasi dijadikan sebagai sampel. Dengan demikian sampel dalam penelitian ini sampel yang digunakan berjumlah 87 responden.

\section{Jenis Penelitian}

Jenis penelitian yang dipakai adalah asosiatif, dimana tujuannya adalah untuk mengetahui atau mencari keterhubungan antara variabel independen terhadap variabel dependennya

\section{Metode Analisis Data}

Dalam menganalisis data digunakan uji validitas, uji reliabilitas, analisis regresi linier sederhana, analisis koefisien korelasi, analisis koefisien determinasi dan pengujian hipotesis.

\section{HASIL PENELITIAN}

\section{Analisis Deskriptif}

Pada pengujian ini digunakan untuk mengetahui skor minimum dan maksimum skor tertinggi, ratting score dan standar deviasi dari masing-masing variabel. Adapun hasilnya sebagai berikut:

Tabel 1. Hasil Analisis Descriptive Statistics

\begin{tabular}{l|r|r|r|r|r}
\multicolumn{7}{c}{ Descriptive Statistics } \\
& N & Minimum & Maximum & Mean & Std. Deviation \\
\hline Motivasi (X) & 87 & 28 & 44 & 33.85 & 4.004 \\
\hline produktivitas Karyawan (Y) & 87 & 29 & 49 & 38.00 & 4.146 \\
\hline Valid N (listwise) & 87 & & & & \\
\hline
\end{tabular}

Motivasi diperoleh varians minimum sebesar 28 dan varians maximum 44 dengan ratting score sebesar 3,385 dengan standar deviasi 4,004. Skor ini termasuk pada rentang sakala 3,40 - 4,19 dengan kriteria baik atau setuju.

Produktivitas karyawan diperoleh varians minimum sebesar 29 dan varians maximum 49 dengan ratting score sebesar 3,800 dengan standar deviasi 4,146. Skor ini termasuk pada rentang sakala 3,40 - 4,19 dengan kriteria baik atau setuju.

\section{Analisis Verifikatif.}

Pada analisis ini dimaksudkan untuk mengetahui pengaruh variabel independen terhadap 
variabel dependen. Adapun hasil pengujian sebagai berikut:

\section{a. Analisis Regresi Linier Sederhana}

Uji regresi ini dimaksudkan untuk mengetahui perubahan variabel dependen jika variabel independen mengalami perubahan. Adapun hasil pengujiannya sebagai berikut:

Tabel 2. Hasil Pengujian Regresi Linier Sederhana

\begin{tabular}{|c|c|c|c|c|c|c|}
\hline \multirow{3}{*}{\multicolumn{2}{|c|}{ Model }} & \multicolumn{3}{|c|}{ Coefficients $^{a}$} & \multirow[b]{3}{*}{$\mathrm{t}$} & \multirow[b]{3}{*}{ Sig. } \\
\hline & & \multicolumn{2}{|c|}{$\begin{array}{l}\text { Unstandardized } \\
\text { Coefficients }\end{array}$} & \multirow{2}{*}{$\begin{array}{c}\text { Standardized } \\
\text { Coefficients } \\
\text { Beta } \\
\end{array}$} & & \\
\hline & & $\mathrm{B}$ & Std. Error & & & \\
\hline 1 & (Constant) & 11.441 & 2.497 & & 4.582 & .000 \\
\hline & Motivasi (X) & .785 & .073 & .758 & 10.710 & .000 \\
\hline
\end{tabular}

a. Dependent Variable: produktivitas Karyawan $(\mathrm{Y})$

Berdasarkan hasil pengujian pada tabel di atas, diperoleh persamaan regresi $\mathrm{Y}=$ 11,441 + 0,785X. Dari persamaan tersebut dijelaskan sebagai berikut:

1) Konstanta sebesar 11,441 diartikan jika motivasi tidak ada, maka telah terdapat nilai produktivitas karyawan sebesar 11,441 point.

2) Koefisien regresi motivasi sebesar 0,785 , angka ini positif artinya setiap ada peningkatan motivasi sebesar 0,785 point maka produktivitas karyawan juga akan mengalami peningkatan sebesar 0,785 point.

\section{b. Analisis Koefisien Korelasi}

Analisis koefisien korelasi dimaksudkan untuk mengetahui tingkat kekuatan hubungan dari variabel independen terhadap variabel dependen. Adapun hasil pengujian sebagai berikut:

Tabel 3. Hasil Pengujian Koefisien Korelasi Motivasi Terhadap Produktivitas Karyawan.

\begin{tabular}{|c|c|c|c|}
\hline \multicolumn{4}{|c|}{ Correlations $^{b}$} \\
\hline & & Motivasi (X) & $\begin{array}{l}\text { produktivitas } \\
\text { Karyawan }(\mathrm{Y})\end{array}$ \\
\hline \multirow[t]{2}{*}{ Motivasi (X) } & Pearson Correlation & 1 & $.758^{\star \star}$ \\
\hline & Sig. (2-tailed) & & .000 \\
\hline \multirow[t]{2}{*}{ produktivitas Karyawan (Y) } & Pearson Correlation & $.758^{* *}$ & 1 \\
\hline & Sig. (2-tailed) & .000 & \\
\hline
\end{tabular}

Berdasarkan hasil pengujian diperoleh nilai korelasi sebesar 0,758 artinya motivasi memiliki hubungan yang kuat terhadap produktivitas karyawan.

\section{c. Analisis Koefisien Determinasi}

Analisis koefisien determinasi dimaksudkan untuk mengetahui besarnya persentase pengaruh dari variabel independen terhadap variabel dependen. Adapun hasil pengujian sebagai berikut:

Tabel 4. Hasil Pengujian Koefisien Determinasi Motivasi Terhadap Produktivitas Karyawan.

\begin{tabular}{|c|c|c|c|c|}
\hline \multirow[b]{2}{*}{ Model } & \multicolumn{3}{|c|}{ Model Summary } & \multirow[b]{2}{*}{$\begin{array}{l}\text { Std. Error of the } \\
\text { Estimate }\end{array}$} \\
\hline & $\mathrm{R}$ & R Square & $\begin{array}{l}\text { Adjusted R } \\
\text { Square }\end{array}$ & \\
\hline 1 & $.758^{\mathrm{a}}$ & .574 & .569 & 2.720 \\
\hline
\end{tabular}


motivasi memiliki kontribusi pengaruh sebesar 57,4\% terhadap produktivitas karyawan, sedangkan sisanya sebesar $42,6 \%$ dipengaruhi oleh faktor lain yang tidak dilakukan penelitian.

\section{d. Uji Hipotesis}

Pengujian hipotesis dengan uji t digunakan untuk mengetahui hipotesis mana yang diterima.

Rumusan hipotesis: Terdapat pengaruh yang signifikan antara motivasi terhadap produktivitas karyawan.

Tabel 5. Hasil Uji Hipotesis Motivasi Terhadap Produktivitas Karyawan.

\begin{tabular}{|c|c|c|c|c|c|c|}
\hline \multicolumn{7}{|c|}{ Coefficients $^{a}$} \\
\hline \multirow{2}{*}{\multicolumn{2}{|c|}{ Model }} & \multicolumn{2}{|c|}{$\begin{array}{l}\text { Unstandardized } \\
\text { Coefficients }\end{array}$} & \multirow{2}{*}{$\begin{array}{c}\text { Standardized } \\
\text { Coefficients } \\
\text { Beta }\end{array}$} & \multirow[b]{2}{*}{$\mathrm{t}$} & \multirow[b]{2}{*}{ Sig. } \\
\hline & & $\mathrm{B}$ & Std. Error & & & \\
\hline \multirow[t]{2}{*}{1} & (Constant) & 11.441 & 2.497 & & 4.582 & .000 \\
\hline & Motivasi (X) & .785 & .073 & .758 & 10.710 & .000 \\
\hline
\end{tabular}

a. Dependent Variable: produktivitas Karyawan $(\mathrm{Y})$

Berdasarkan hasil pengujian pada tabel di atas, diperoleh nilai $\mathrm{t}$ hitung $>\mathrm{t}$ tabel atau $(10,710>1,988)$, dengan demikian hipotesis yang diajukan bahwa terdapat pengaruh yang signifikan atara motivasi terhadap produktivitas karyawan diterima.

\section{Pembahasan Hasil Penelitian}

\section{Kondisi Jawaban Responden Variabel Motivasi}

Berdasarkan jawaban responden, variabel motivasi diperoleh ratting score sebesar 3,385 berada di rentang skala 3,40-4,19 dengan kriteria baik atau setuju.

\section{Kondisi Jawaban Responden Variabel Produktivitas Karyawan}

Berdasarkan jawaban responden, variabel produktivitas karyawan diperoleh ratting score sebesar 3,800 berada di rentang skala 3,40 - 4,19 dengan kriteria baik atau setuju.

\section{Pengaruh Motivasi Terhadap Produktivitas Karyawan}

Motivasi berpengaruh signifikan terhadap produktivitas karyawan dengan persamaan regresi $\mathrm{Y}=11,441+0,785 \mathrm{X}$, nilai korelasi sebesar 0,758 atau memiliki hubungan yang kuat dengan kontribusi pengaruh sebesar 57,4\%. Pengujian hipotesis diperoleh nilai t hitung $>t$ tabel atau $(10,710>1,988)$. Dengan demikian hipotesis yang diajukan bahwa terdapat berpengaruh signifikan antara motivasi terhadap produktivitas karyawan diterima.

\section{KESIMPULAN DAN SARAN}

\section{Kesimpulan}

a. Variabel motivasi diperoleh ratting score sebesar 3,385 berada di rentang skala 3,40 4,19 dengan kriteria baik atau setuju.

b. Variabel produktivitas karyawan diperoleh ratting score sebesar 3,800 berada di rentang skala 3,40-4,19 dengan kriteria baik atau setuju.

c. Motivasi berpengaruh signifikan terhadap produktivitas karyawan dengan persamaan regresi $\mathrm{Y}=11,441+0,785 \mathrm{X}$, nilai korelasi sebesar 0,758 atau kuat dan kontribusi pengaruh sebesar $57,4 \%$ sedangkan sisanya sebesar $42,6 \%$ dipengaruhi faktor lain. Uji hipotesis diperoleh nilai $t$ hitung $>\mathrm{t}$ tabel atau $(10,710>1,988)$. 


\section{Saran}

1. Variabel motivasi, indikator yang paling lemah adalah kebutuhan rasa aman terutama pada pernyataan merasa tenang dalam bekerja karena tersedia jaminan kesehatan dari perusahaan dimana hanya mencapai score 3,78 meskipun termasuk dalam kategori baik namun mengingat motivasi kerja juga merupakan salah satu variabel penting dalam memaksimalkan produktivitas kerja perusahaan maka perusahaan harus mendorong semua karyawan agar dapat menentukan prioritas kerja dan memberi kesempatan pada karyawan untuk di promosikan ke bagian yang lebih tinggi ketika memang memiliki skill dan kemampuan yang baik. Dengan demikian, karyawan yang termotivasi akan melakukan usaha yang lebih besar, memiliki kecakapan dalam menunjang aktivitas pekerjaannya.

2. Variabel produktivitas kerja karyawan, indikator yang paling lemah adalah Indikator Mempunyai kontribusi positif pada perusahaan terutama pada pernyataan ketepatan waktu dan kesempurnaan hasil pekerjaan dimana hanya mencapai score 3,75 meskipun termasuk dalam kategori baik namun mengingat produktivitas kerja karyawan juga merupakan salah satu variabel penting dalam kinerja perusahaan secara keseluruhan, maka perusahaan harus mendorong karyawan memiliki integritas dalam mencapai performa kerja yang sebaik-baiknya agar kesemuanya dapat menunjang bidang pekerjaan masing-masing bagian kerja.

3. Kontibusi pengaruh motivasi dan disiplin kerja secara simultan terhadap produktivitas kerja karyawan sebesar 53\%, nilai ini masih bisa ditingkatkan dengan secara selektif dapat memprioritaskan pesanan pelanggan yang harus dipenuhi dan kondisi masingmasing variabel bebas harus ditingkatkan secara signifikan. Oleh karenanya disarankan kepada penelitian berikutnya agar melakukan penelitian yang relevan dengan cara memperbaiki indikator yang masih tidak baik atau dengan menambah indikator pertanyaan dan jumlah responden penelitian sehingga akan dapat lebih diketahui variabel yang paling memberikan kontribusi positif bagi perusahaan.

\section{DAFTAR PUSTAKA}

A.A Anwar Prabu Mangkunegara, "Sumber Kerangka Berfikir Kinerja”. Gramedia, Jakarta Selatan, 2014.

Agung Nugroho, "Strategi Jitu Dalam Memilih Metode Statistik Peneltian", Andi, Yogyakarta, 2012.

Algifari, "Analisis Regresi”, Yogyakarta, 2011.

Andi Supangat, "Statistika dalam Kajian Deskriftif, Inferensi dan Non Parametric", Edisi Pertama, Kencana Prenada Media Group, Jakarta, 2014.

Arikunto, Suharsimi, "Prosedur Penelitian Suatu Pendekatan Praktek”, PT. Rineka Cipta, Jakarta, 2015.

Bernardin, H. John dan Joyce E.A. Russell, "Human Resource Management”, An Experiential Approach, McGrow Hill, Singapore, 2013.

Bilson Simamora "Panduan Riset Prilaku Konsumen”, PT. Gramedia Pustaka, Jakarta, 2012.

Dessler, Gerry, "Human Resources Management", Prenticehall, International Inc, London, 2014.

Edi Sutrisno “Sumber Daya Manusia”, PT. Gramedia, Surabaya, 2012.

Edwin B Flippo, "Prinsip-Prinsip Sumber Daya Manusia”, Edisi ke Duabelas, Erlangga, 
Jakarta, 2014.

Follet dalam Sule, "Pengantar Manajemen”, Kencana, Jakarta, 2014.

G.R. Terry, and Rue, Leslie W. Rue, "Dasar-dasar Manajemen”, Bumi Aksara, Jakarta 2014. Ghozali, Imam, “Aplikasi Analisis Multivariate dengan Program SPSS”, Edisi Kelima, Badan Penerbit Undip, Semarang, 2014.

Handoko, "Manajemen Personalia dan Sumberdaya Manusia", Edisi Kelima, BPFE UGM, Yogyakarta, 2012.

Hasibuan, "Sumber Daya Manusia”, Haji Masagung, Jakarta, 2016.

Ilham, D. (2014). Implementasi Nilai-Nilai Keagamaan pada Mata Pelajaran Umum dalam Upaya Peningkatan Akhlak Peserta Didik di MAN Malili Kabupaten Luwu Timur (Doctoral dissertation, STAIN/IAIN Palopo).

Ilham, D. (2019). Implementing Local Wisdom Values in Bride and Groom Course at KUA Bara SubDistrict, Palopo City. Jurnal Konsepsi, 8(1), 1-9.

Ilham, D. (2019). Menggagas Pendidikan Nilai dalam Sistem Pendidikan Nasional. Didaktika: Jurnal Kependidikan, 8(3), 109-122.

Istijianto, “Aplikasi Praktis Riset Pemasaran”, Gramedia Pustaka Utama, Jakarta, 2012.

J. Supranto, Statistik Teori dan Aplikasi, Edisi ketujuh Jilid 2: Jakarta, 2013.

Jonathan Sarwono, "Metode Penelitian Kuantitatif Dan Kualitatif", Graha Ilmu, Yogyakarta, 2012

Luthans, Fred, “Organizational Behavior:, McGraw-Hill, New York, 2012.

Mathis, Robert L dan John H. Jackson. "Manajemen Sumber Daya Manusia", Buku Dua. Salemba Empat: Jakarta, 2014.

Mathis, Robert. L \& Jackson John.H, "Manajemen Sumber Daya Manusia” Jilid 1, Salemba Empat, Jakarta, 2014.

Michael R Carrell, "Human Resourcee Managemen Global for managing Diverse Wokplace”, Edition, Prenice Hall Inc. Nre Jersey, 2015.

Miftah Thoha "Kepemimpinan Dalam Manajemen", Edisi Pertama, PT. Raja Grafindo, Jakarta, 2012.

Mulyadi, M. (2018). Pengaruh Pelatihan Dan Motivasi Terhadap Kinerja Karyawan Pada PT. Permata Lestari. JENIUS (Jurnal Ilmiah Manajemen Sumber Daya Manusia), 2(1).

Panji Anoraga "Psikologi Kerja”, Rineka Cipta, Jakarta, 2014.

Rivai, Veithzal, "Manajemen Sumber Daya Manusia Untuk Perusahaan”, Raja Grafindo Persada, Jakarta, 2013.

Robbins, Stephen dan Mary Coulter, “Manajemen”, PT. Indeks Kelompok Gramedia, Jakarta, 2012.

Safroni Ladzi, "Manajemen dan Reformasi Pelayanan Publik dalam Konteks Birokrasi Indonesia”, Aditya Media Publishing, Surabaya 2012.

Salam, “Manajemen Pemerintahan Indonesia”. PT. Djambatan, Jakarta, 2014.

Santoso, Singgih, "SPSS Statistik Parametik” Cetakan Kedua, PT. Elek Media, 2015.

Sarwono, Jonathan, "Metode Penelitian Kuantitatif Dan Kualitatif", Graha Ilmu, Yogyakarta, 2012

Sarwono, Jonathan, "Metode Penelitian Kuantitatif Dan Kualitatif”, Graha Ilmu, Yogyakarta, 2012

Sarwoto, "Dara-Dasar Manajemen Sumber Daya Manusia”, Cetakan Keenambelas, Ghalia Indonesia, Jakarta, 2011.

Sedarmayanti. "Manajemen Sumber Daya Manusia, Reformasi Birokrasi dan Manajemen Pegawai Negeri Sipil”, Cetakan Kelima, PT Refika Aditama, Bandung, 2014.

Siagian Sondang P, “Kiat Meningkatkan Produktivitas Kerja”, PT. Rineka Cipta, Jakarta, 2012. 
Simamora, Bilson, “Panduan Riset Dan Perilaku Konsumen”, PT. Gramedia Pustaka Utama, Jakarta, 2014.

Singgih Santoso "SPSS Statistik Parametik" Cetakan Kedua, PT. Elek Media, Jakarta, 2013.

Siswanto dan Agus, "Manajemen Sumber Daya Manusia” PT. Gramedia Pustaka, Jakarta, 2013.

Sudjana, "Metode Statistika", Edisi Keenam, Tarsito, Bandung, 2011.

Sugiyono, "Metode Penelitian Kuantitatif Kualitatif dan R \& D", Penerbit CV. Alfabeta, Bandung, 2016.

Suharsimi Arikunto "Prosedur Penelitian Suatu Pendekatan Praktek", PT. Rineka Cipta, Jakarta, 2013.

Suherman, Wawan, "Kurikulum Berbasis Kompetensi Pendidikan Jasmani Teori dan Praktik Pengembangan", FIK UNY, Yogyakarta, 2012

Sunarsi, D. (2018). Pengembangan Sumber Daya Manusia Strategik \& Karakterisrik Sistem Pendukungnya : Sebuah Tinjauan. Jurnal Ilmiah MEA (Manajemen, Ekonomi, \& Akuntansi), 2(3), 178 - 194. https://doi.org/10.31955/mea.vol2.iss3.pp178 - 194

Supranto, "Statistik Teori dan Aplikasi”, Pustaka Ekonomi, Jakarta, 2013.

Suryani, N. L. (2018). Pengaruh Gaya Kepemimpinan Dan Motivasi Terhadap Kinerja Karyawan Pada PT. Boga Lestari Sentosa (Kenny Rogers Roasters) Indonesia. JENIUS (Jurnal Ilmiah Manajemen Sumber Daya Manusia), 2(1).

Sutrisno, Edi., 2014. Pengaruh Disiplin kerja dan Budaya Organisasi Terhadap Kinerja Karyawan Devisi Radiologi RSUD Karidi Semarang” Vol. 12 No.2.

Syofian Siregar, "Statistika Deskriptif Untuk Penelitian”, PT Raja Grafindo Persada, Jakarta, 2011.

Tb. Sjaftri Mangkuprawira (2010:135) “Pengertian Pelatihan”. Gramedia, Jakarta Pusat, 2014.

Terry, George R \& Rue, Leslie W. Rue, “Dasar-Dasar Manajemen”, Jakarta Bumi Aksara, Jakarta, 2010.1

Thomas $S$. dan Snell, Scott A, “Management The New Competitive”, Landscape. Sixth Edition. McGraw Hill. New York, 2013.

Veithzal Rivai, "Proses Arti Pelatihan”. Jakarta, 2014.

W.F. Cascio dalam Robbins, "Managing Human resources productivity of Work”, Edisi ketujuh, terjemahan, Jakarta, 2012.

Wawan S. Suherman, "Kurikulum Berbasis Kompetensi Pendidikan Jasmani Teori dan Praktik Pengembangan", FIK UNY, Yogyakarta, 2013.

Wibowo, “Manajemen Kinerja”, PT. Raja Grafindo Persada, Jakarta, 2014. 